\title{
FAKTOR YANG MEMENGARUHI RUJUKAN PASIEN PENGGUNA JKN-PBI KE FASILITAS KESEHATAN TINGKAT LANJUT DI PUSKESMAS PANCUR BATU KABUPATEN DELI SERDANG TAHUN 2019
}

\author{
Diana Sinulingga, Linda Silalahi \\ Institut Kesehatan Deli Husada Deli Tua \\ e-mail: dianasinulinga1951@yahoo.com
}

\begin{abstract}
BPJS complains that the puskesmas still carry out unnecessary referral actions (non-specialized diseases) to hospitals. The purpose of this study is to analyze the factors that influence the referral of PBI JKN patient patients to advanced health facilities. This is quantitative research with survey method through cross sectional approach. The research was conducted at Pancur Batu Puskesmas Deli Serdang District. The study population was 18,459 people and the sample was 186 people with purposive sampling techniques. Data analysis used univariate analysis, bivariate analysis with chi-square, and multivariate analysis using multiple logistic regression tests. The results showed that the factors that influenced were knowledge, availability of infrastructure and information about referrals, $p<0.05$. Variables that do not affect are distance, motivation, attitudes of health workers, $p>0.05$. The variable that has the greatest influence in this study is the variable availability of infrastructure with the value of $\operatorname{Exp}(B) / O R=6.810$ means that respondents who stated that the availability of infrastructure in hospitals was adequate, had the chance to be referred to 6.8 times higher than respondents who stated the availability of infrastructure facilities in hospitals is inadequate. It is recommended that the Pancur Batu Puskesmas repair some Puskesmas infrastructure facilities that are considered incomplete and less satisfying for some patients so that patients do not ask for referrals for diseases that can be treated at the Puskesmas.
\end{abstract}

Keywords: patient referral, JKN-PBI, FKTL

\section{PENDAHULUAN}

Sejak digulirkan program Badan Penyelenggara Jaminan Sosial (BPJS) sampai tanggal 31 Desember 2017 peserta Jaminan Kesehatan Nasional-Kartu Indonesia Sehat (JKNKIS) mencapai 187.982.949 jiwa, artinya jumlah masyarakat yang telah mengikuti program Jaminan Kesehatan Nasional-Kartu Indonesia Sehat (JKN-KIS) hampir mencapai $72,9 \%$ dari jumlah penduduk Indonesia, dengan kata lain masih terdapat sekitar $27,1 \%$ lagi masyarakat yang belum menjadi peserta JKN-KIS. Hal itu selaras dengan arah kebijakan dan strategi nasional dalam Rencana Pembangunan Jangka Menengah Nasional (RPJMN) tahun 2019, bahwa target minimal mencakup 95\% pada tahun 2019 (BPJS, 2018).

Berkaitan dengan masalah rujukan, BPJS Kesehatan mengeluhkan masih tingginya puskesmas melakukan tindak rujukan yang tidak perlu (penyakit nonspesialisasi) ke Fasilitas Kesehatan Tingkat Lanjut (FKTL) atau rumah sakit. Tercatat 14,6 juta peserta program JKN yang dikelola BPJS Kesehatan berobat di fasilitas kesehatan tingkat pertama (FKTP), seperti puskesmas, klinik pratama, dan dokter praktik pribadi. Dari total itu, sebanyak 2,2 juta pasien yang berobat di FKTP, khususnya di puskesmas, sekitar 15,3\% di antaranya dirujuk ke FKTL. Hasil evaluasi dan monitoring yang dilakukan BPJS Kesehatan, dari total pasien yang dirujuk tersebut, 214.706 kasus di antaranya terbukti tidak perlu dirujuk ke RS, cukup diobati di tingkat FKTP (Jamkes Indonesia, 2019).

Data BPJS Kesehatan Wilayah Sumut dan Aceh, bahwa melalui Program JKA Plus dan Sumut Sehat telah melakukan integrasi terhadap Program JKN-KIS. Untuk Kabupaten/Kota yang telah melakukan integrasi terhadap Program JKN-KIS sebanyak 56 kabupaten/kota se-Sumatera Utara dan Aceh dengan jumlah peserta 3.233.880 jiwahingga 22 Desember 2017. Kabupaten/Kota yang sudah menjadi peserta JKN-KIS atau Universal Health Coverage (UHC) pada tahun 2017 adalah 23 kabupaten/kota di Aceh ditambah 4 kabupaten/kota di Sumatera Utara (Jamkesda 


\begin{tabular}{l|r|r}
\hline Jurnal Penelitian Kesmasy & Vol. 2 No. 1 & Edition: May - October 2019 \\
\hline \multirow{2}{*}{ Received: 24 October 2019 } & http://ejournal.delihusada.ac.id/index.php/JPKSY & \\
\cline { 2 - 2 } & Revised: 28 October 2019 & Accepted: 31 October 2019
\end{tabular}

Kota Sibolga, Kabupaten Nias Utara, Kabupaten Pakpak Bharat, dan Kota Binjai) dengan jumlah peserta sejumlah 2.195.609 jiwa (Wartaekonomi, 2018).

Peserta JKN-KIS yang terdaftar di Kabupaten Deli Serdang hingga 1 Desember 2017, berjumlah 894.023 jiwa dari 1.938.121 jiwa penduduk yang ada di Kabupaten Deli Serdang atau sekitar $46 \%$ dari total jumlah penduduk Kabupaten Deli Serdang. Pemerintah Kabupaten Deli Serdang berharap pada 31 Desember 2018 sebesar $98 \%$ penduduk Deli Serdang sudah masuk ke dalam program Jaminan Kesehatan Nasional-Kartu Indonesia Sehat (JKN-KIS) (BPJS, 2017).

Puskesmas di era JKN memiliki peran yang
besar kepada peserta BPJS kesehatan. Puskesmas merupakan salah satu wujud nyata penyediaan layanan publik di bidang kesehatan yang bermutu namun dengan biaya yang relatif terjangkau untuk masyarakat, terutama masyarakat dengan kelas ekonomi menengah ke bawah(Rumengan et.al., 2015). Pelayanan kesehatan yang diterima oleh peserta BPJS dilaksanakan melalui mekanisme rujukan berjenjang. Pada FKTP, peserta berobat ke faskes primer seperti puskesmas, klinik, atau dokter keluarga yang tercantum pada kartu peserta BPJS Kesehatan. Apabila peserta memerlukan pelayanan lanjutan oleh dokter spesialis, maka peserta dapat dirujuk ke fasilitas kesehatan tingkat kedua atau fasilitas kesehatan sekunder. Jika penyakit peserta masih belum dapat ditangani pada fasilitas kesehatan sekunder, maka peserta dapat dirujuk ke fasilitas kesehatan tersier (BPJS Kesehatan, 2014).

Andersen and Newman membuat suatu kerangka kerja teoritis untuk pemanfaatan pelayanan kesehatan yang digunakan dalam penelitian ini untuk mengukur penggunaan pelayanan rujukan kesehatan ke fasilitas kesehatan tingkat lanjut. Andersen menggambarkan model sistem kesehatan (health system model) berupa model kepercayaan kesehatan (Andersen \& Newman, 1973). Menurutnya, terdapat 3 kategori utama dalam pelayanan kesehatan yakni karakteristik: predisposisi, pendukung, maupun kebutuhan. Karakteristik predisposisi meliputi faktor demografi; terdiri dari umur, jenis kelamin dan status perkawinan. Struktur sosial; terdiri dari tingkat pendidikan, pekerjaan dan ras. kepercayaan terdiri dari keyakinan, persepsi atau pandangan terhadap pelayanan kesehatan, pengetahuan, sikap, dan motivasi. Karakteristik pendukung terdiri dari sumber daya keluarga (pendapatan, cakupan asuransi), kualitas pelayanan dan jarak. Karakteristik kebutuhan terdiri dari tarif, fasilitas, pelayanan personil, lokasi, kecepatan pelayanan, dan informasi (Notoatmodjo, 2016).

Puskesmas Pancur Batu adalah puskesmas induk yang ada di Kabupaten Deli Serdang. Berdasarkan data yang diperoleh dari Puskesmas Pancur Batu bahwa jumlah penduduk yang tercatat dalam profil Puskesmas Pancur Batu sebanyak 86.800 jiwa dengan jumlah Kepala Keluarga (KK) sebanyak 21.218 KK dan jumlah peserta JKN sampai dengan bulan Desember 2018 sebanyak 30.825 orang atau sekitar $35,5 \%$ dari seluruh masyarakat yang ada di Wilayah Kerja Puskesmas Pancur Batu Kabupaten Deli Serdang. Jumlah peserta JKN kategori Penerima Bantuan Iuran (PBI) sebanyak 18.459 orang dan non PBI sebanyak 12.366 orang (Puskesmas Pancur Batu, 2018). PBI adalah peserta Jaminan Kesehatan bagi fakir miskin dan orang tidak mampu sebagaimana diamanatkan UU SJSN yang iurannya dibayari Pemerintah sebagai peserta program Jaminan Kesehatan (BPJS Kesehatan, 2014).

Berdasarkan data kunjungan dan rujukan pasien di Puskesmas Pancur Batu periode Juli 2018 - Desember 2018 bahwa jumlah kunjungan seluruhnya sebanyak 6.036 kunjungan sedangkan jumlah rujukan 1.561 rujukan, diantaranya pasien JKN yang dirujuk ke FKTL sebanyak 706 rujukan $(47,1 \%)$. Tingginya Persentase Rujukan di Puskesmas Pancur Batu tersebut menjadi permasalahan dan harus diminimalisir karena sesuai dengan standar penetapan dari BPJS, persentase pencapaian pelayanan rujukan idealnya tidak lebih dari $15 \%$. Rumah sakit rujukan pasien khususnya peserta JKN PBI dari Puskesmas Pancur Batu yaitu Rumah Sakit Adam Malik Medan, Rumah Sakit Bina Kasih Medan, Rumah Sakit Sembiring Delitua, sedangkan pasien peserta JKN non PBI meminta rujukan ke Rumah Sakit SitiHajar, Rumah Sakit Elisabeth Medan, Rumah Sakit Bunda Thamrin dan beberapa rumah sakit lainnya (Puskesmas Pancur Batu, 2019a).

Survei pendahuluan dengan mewawancarai 20 peserta JKN PBI yang berobat ke Puskesmas Pancur Batu, sebanyak 13 orang (65\%) mendapatkan pengobatan di Puskesmas Pancur Batu sedangkan 7 orang lainnya (35\%) meminta surat rujukan untuk mendapatkan pelayanan ke fasilitas kesehatan tingkat lanjut (FKTL). Alasan mereka meminta surat rujukan karena tidak tersedianya fasilitas yang mereka butuhkan di Puskesmas Pancur Batu seperti rawat inap untuk perawatan sakit jantung, sakit mata, THT. Ada 


\begin{tabular}{l|r|r}
\hline Jurnal Penelitian Kesmasy & Vol. 2 No. 1 & Edition: May - October 2019 \\
\hline & http://ejournal.delihusada.ac.id/index.php/JPKSY & \\
\cline { 2 - 2 } Received: 24 October 2019 & Revised: 28 October 2019 & Accepted: 31 October 2019
\end{tabular}

juga yang beralasan bahwa pelayanan di Puskesmas Pancur Batu kurang menyenangkan bagi mereka karena petugasnya kurang ramah, kurang komunikatif, ada yang merasa kurang percaya dengan pelayanan di puskesmas dan lebih merasa percaya dengan pelayanan di rumah sakit. Dilihat dari banyaknya kasus rujukan tersebut menunjukkan bahwa implementasi aspek kebijakan sistem rujukan di Puskesmas Pancur Batu belum berjalan dengan baik dilihat dari tingginya rasio rujukan melebihi dari standar ketetapan BPJS Kesehatan yaitu 15\%.

\section{METODE}

Jenis penelitian adalah penelitian kuantitatif dengan metode survei, dengan pendekatan potong lintang (Cross Sectional). Penelitian ini dilaksanakan di Puskesmas Pancur Batu Kabupaten Deli Serdang. Populasi penelitian ini adalah seluruh peserta JKN PBI sebanyak 18.459 orang. Sampel diperoleh 186 orang. Data yang digunakan adalah data primer dan sekunder. Data dianalisis menggunakan analisis univariat, dan bivariat dengan uji chi-square, analisis multivariat dengan menggunakan uji regresi regresi logistik berganda pada taraf kepercayaan $95 \%$.

\section{HASIL DAN PEMBAHASAN}

Karakteristik responden yaitu menunjukkan bahwa sebagian besar responden berumur $>49$ tahun $(52,7 \%)$, selebihnya berumur $<49$ tahun $(47,3 \%)$. Sebagian besar responden berjenis kelamin laki-laki $(51,1 \%)$, selebihnya perempuan (48,9\%). Pendidikan responden yaitu (SMA) $(52,7 \%)$, sebagian kecil berpendidikan D3/S1/S2 $(10,2 \%)$. Berdasarkan pekerjaan sebagian besar bekerja sebagai PNS/Pegawai Swasta/petani/ pedagang/buruh) sebanyak $53,2 \%$, sebagian kecil tidak bekerja (Ibu rumah tangga/pensiunan/ pengangguran) sebanyak 46,8\%. Berdasarkan pendapatan, dikategorikan menurut UMK Deli Serdang tahun 2019 sebesar Rp.2.938.254, bahwa sebagian besar pendapatan keluarga responden kurang dari Rp. 2.938.254.00 (57,0\%), sebagian kecil pendapatan keluarga responden lebih dari Rp. 2.938.254.00 (43,0\%).

Data penelitian menunjukkan bahwa sebagian besar responden berpengetahuan baik $(60,8 \%)$, berpengetahuan kurang baik $(39,2 \%)$. Motivasi responden dalam kategori tinggi $(51,6 \%)$, motivasi rendah $(48,4 \%)$. Responden menyatakan sikap petugas kesehatan dalam kategori baik (74,2\%),yang menyatakan sikap petugas kesehatan dalam kategori kurang baik $(25,8 \%)$. Jarak tempat tinggal responden ke puskesmas dalam kategori jauh (61,3\%),sebagian kecil dekat $(38,7 \%)$. Sebagian besar responden menyatakan sarana prasarana di puskesmas memadai (63,4\%),yang menyatakan sarana prasarana tidak memadai (36,6\%). Sebagian besar responden mendapat informasi rujukan dalam kategori baik $(74,7 \%)$,sebagian kecil responden mendapat informasi rujukan dalam kategori kurang baik (25,3\%). Berdasarkan rujukan, menunjukkan bahwa sebagian besar responden tidak dirujuk sebanyak 109 orang $(58,6 \%)$, sedangkan responden yang dirujuk ke fasilitas kesehatan tingkat lanjut sebanyak 77 orang (41,4\%).

Tabel 1. Pengaruh Pengetahuan terhadap Rujukan Pasien Pengguna JKN-PBI ke FKTL di Puskesmas Pancur Batu Kabupaten Deli Serdang

\begin{tabular}{|c|c|c|c|c|c|c|c|}
\hline \multirow{3}{*}{$\begin{array}{l}\text { Pengeta- } \\
\text { huan }\end{array}$} & \multicolumn{4}{|c|}{ Rujukan ke FKTL } & \multirow{2}{*}{\multicolumn{2}{|c|}{ Jumlah }} & \multirow{3}{*}{$\begin{array}{c}p- \\
\text { - value }\end{array}$} \\
\hline & \multicolumn{2}{|c|}{ Dirujuk } & \multicolumn{2}{|c|}{ Tidak } & & & \\
\hline & f & $\%$ & $\mathbf{f}$ & $\%$ & $\mathbf{f}$ & $\%$ & \\
\hline Baik & 40 & 35,4 & 73 & 64,6 & 113 & 100 & 0.048 \\
\hline Kurang & 37 & 50,7 & 36 & 49,3 & 73 & 100 & 0,048 \\
\hline
\end{tabular}

Hasil uji bivariat diperoleh $p$-value sebesar $0,048<0,05$ artinya ada pengaruh pengetahuan terhadap rujukan pasien pengguna JKN PBI ke FKTL di Puskesmas Pancur Batu Kabupaten Deli Serdang tahun 2019.

Tabel 2. PengaruhMotivasi terhadap Rujukan Pasien Pengguna JKN PBI ke FKTLdi Puskesmas Pancur Batu Kabupaten Deli Serdang

\begin{tabular}{ccccccccc}
\hline \multirow{2}{*}{ Motivasi } & \multicolumn{9}{c}{ Rujukan ke FKTL } & \multirow{2}{*}{ Jumlah } & \multirow{2}{*}{$\boldsymbol{p}$ - } \\
\cline { 2 - 8 } & \multicolumn{2}{c}{ Dirujuk } & \multicolumn{2}{c}{ Tidak } & & & value \\
\cline { 2 - 8 } & $\mathbf{f}$ & $\mathbf{\%}$ & $\mathbf{f}$ & $\mathbf{\%}$ & $\mathbf{f}$ & $\mathbf{\%}$ & \\
\hline Tinggi & 42 & 50,6 & 41 & 49,4 & 83 & 100 & \multirow{2}{*}{0,025} \\
Rendah & 35 & 34,0 & 68 & 66,0 & 103 & 100 & \\
\hline
\end{tabular}

Hasil uji bivariat diperoleh $p$-value sebesar $0,025<0,05$ artinya ada pengaruh motivasi terhadap rujukan pasien pengguna JKN PBI ke FKTL di Puskesmas Pancur Batu Kabupaten Deli Serdang tahun 2019.

Tabel 3. Pengaruh Sikap Petugas Kesehatan terhadap Rujukan Pasien Pengguna JKN PBI ke FKTL di Puskesmas Pancur Batu Kabupaten Deli Serdang

\begin{tabular}{|c|c|c|c|c|c|c|c|}
\hline \multirow{3}{*}{$\begin{array}{c}\text { Sikap } \\
\text { Petugas } \\
\text { Kesehatan }\end{array}$} & \multicolumn{4}{|c|}{ Rujukan ke FKTL } & \multirow{2}{*}{\multicolumn{2}{|c|}{ lumlah }} & \multirow{3}{*}{$\underset{\text { value }}{p-}$} \\
\hline & \multicolumn{2}{|c|}{ Dirujuk } & \multicolumn{2}{|c|}{ Tidak } & & & \\
\hline & $f$ & $\%$ & $f$ & $\%$ & 1 & $\%$ & \\
\hline & 42 & & & & 8 & & \\
\hline Rendah & 35 & 34, & 68 & 66,0 & 103 & 100,0 & \\
\hline
\end{tabular}

Hasil uji bivariat diperoleh $p$-value sebesar $0,042<0,05$ artinya ada pengaruh sikap petugas 
kesehatan terhadap rujukan pasien pengguna JKN PBI ke FKTL di Puskesmas Pancur Batu Kabupaten Deli Serdang tahun 2019.

Tabel 4. PengaruhJarak terhadap Rujukan Pasien Pengguna JKN PBI ke FKTL di Puskesmas Pancur Batu Kabupaten Deli Serdang

\begin{tabular}{ccccccccc}
\hline \multirow{3}{*}{ Jarak } & \multicolumn{4}{c}{ Rujukan ke FKTL } & \multirow{2}{*}{ Jumlah } & \multirow{2}{*}{$\boldsymbol{p}$ - } \\
\cline { 2 - 7 } & \multicolumn{2}{c}{ Dirujuk } & \multicolumn{2}{c}{ Tidak } & & & value \\
\cline { 2 - 7 } & f & \% & f & \% & f & \% & \\
\hline Jauh & 44 & 38,6 & 70 & 61,4 & 114 & 100 & \multirow{2}{*}{0,361} \\
Dekat & 33 & 45,8 & 39 & 54,2 & 72 & 100 & \\
\hline
\end{tabular}

Hasil uji bivariat diperoleh $p$-value sebesar $0,361>0,05$ artinya tidak ada pengaruh jarak terhadap rujukan pasien pengguna JKN PBI ke FKTL di Puskesmas Pancur Batu Kabupaten Deli Serdang tahun 2019.

Tabel 5. Pengaruh Ketersediaan Sarana Prasarana terhadap Rujukan Pasien Pengguna JKN PBI ke FKTL di Puskesmas Pancur Batu Kabupaten Deli Serdang

\begin{tabular}{|c|c|c|c|c|c|c|c|}
\hline \multirow{3}{*}{$\begin{array}{c}\text { Ketersediaan } \\
\text { Sarana } \\
\text { Prasarana }\end{array}$} & \multicolumn{4}{|c|}{ Rujukan ke FKTL } & \multirow{2}{*}{\multicolumn{2}{|c|}{ Jumlah }} & \multirow{3}{*}{$\begin{array}{c}p- \\
\text { value }\end{array}$} \\
\hline & \multicolumn{2}{|c|}{ Dirujuk } & \multicolumn{2}{|c|}{ Tidak } & & & \\
\hline & $f$ & $\%$ & $f$ & $\%$ & $\mathbf{f}$ & $\%$ & \\
\hline Memadai & 30 & 25,4 & 88 & 74,6 & 118 & 100 & \\
\hline Tidak & 47 & 69,1 & 21 & 30,9 & 68 & 100 & \\
\hline
\end{tabular}

Hasil uji bivariat diperoleh $p$-value sebesar $0,000<0,05$ artinya ada pengaruh ketersediaan sarana prasarana terhadap rujukan pasien pengguna JKN PBI ke Fasilitas Kesehatan Tingkat Lanjut (FKTL) di Puskesmas Pancur Batu Kabupaten Deli Serdang tahun 2019.

Tabel 6. PengaruhInformasi Rujukan terhadap Rujukan Pasien Pengguna JKN PBI ke FKTL di Puskesmas Pancur Batu Kabupaten Deli Serdang

\begin{tabular}{|c|c|c|c|c|c|c|c|}
\hline \multirow{3}{*}{$\begin{array}{c}\text { Informasi } \\
\text { Rujukan }\end{array}$} & \multicolumn{4}{|c|}{ Rujukan ke FKTL } & \multirow{2}{*}{\multicolumn{2}{|c|}{ Jumlah }} & \multirow{3}{*}{$\begin{array}{c}p- \\
\text { value }\end{array}$} \\
\hline & \multicolumn{2}{|c|}{ Dirujuk } & \multicolumn{2}{|c|}{ Tidak } & & & \\
\hline & $\mathbf{f}$ & $\%$ & $\mathbf{f}$ & $\%$ & $\mathbf{f}$ & $\%$ & \\
\hline & 45 & 32,4 & 94 & 67,6 & 139 & 100 & \\
\hline Kurang & 32 & 68,1 & 15 & 31,9 & 47 & 100 & \\
\hline
\end{tabular}

Hasil uji bivariat diperoleh $p$-value sebesar $0,000<0,05$ artinya ada pengaruh informasi rujukan terhadap rujukan pasien pengguna JKN PBI ke FKTL di Puskesmas Pancur Batu Kabupaten Deli Serdang tahun 2019.

Variabel yang dijadikan kandidat model pada uji regresi logistik berganda pada penelitian ini karena memiliki nilai signifikan $<0,25$ yaitu sebanyak 5 variabel terdiri dari pengetahuan ( $p=$ $0,048)$, motivasi $(p=0,025)$, sikap petugas kesehatan $(p=0,042)$, ketersediaan sarana prasarana $(p=0,000)$ dan informasi tentang rujukan $(p=0,000)$. Sedangkan variabel yang tidak masuk sebagai kandidat adalah jarak $(\mathrm{p}=$ 0,361 ).

Tabel 7. Seleksi Variabel yang Menjadi Kandidat Model dalam Uji Regresi Logistik Berganda Berdasarkan Analisis Bivariat

\begin{tabular}{clc}
\hline No & \multicolumn{1}{c}{ Variabel } & $\begin{array}{c}\text { Sig. ( } \boldsymbol{p} \text { - } \\
\text { value })\end{array}$ \\
\hline 1 & Pengetahuan & 0,048 \\
2 & Motivasi & 0,025 \\
3 & Sikap petugas kesehatan & 0,042 \\
4 & Jarak & $0,361^{*}$ \\
5 & Ketersediaan sarana prasarana & 0,000 \\
6 & Informasi tentang rujukan & 0,000 \\
\hline * Tidak masuk dalam model karena memiliki nilai $p>0,25$
\end{tabular}

Hasil uji regresi logistik berganda menunjukkan bahwa sebanyak 3 variabel yang berpengaruh terhadap rujukan ke FKTL yaitu pengetahuan, ketersediaan sarana prasarana dan informasi tentang rujukan.

Berdasarkan hasil uji regresi logistik berganda tersebut nilai signifikan model secara bersama-sama diperoleh sebesar 0,000 $<0,05$ yang berarti bahwa ketiga variabel yang dijadikan model dalam penelitian ini memiliki pengaruh yang signifikan terhadap rujukan ke FKTL.

Tabel 8. Hasil Uji Regresi Logistik Ganda

\begin{tabular}{lcccc}
\hline \multicolumn{1}{c}{ Variabel } & B & Sig. & $\begin{array}{c}\text { Exp } \\
\text { (B) }\end{array}$ & $\begin{array}{c}\text { 95\% CI for } \\
\text { Exp(B) }\end{array}$ \\
\hline Pengetahuan & 0,951 & 0,008 & 2,588 & $1,278-5,243$ \\
Ketersediaan & 1,918 & 0,000 & 6,810 & $3,339-13,886$ \\
Sarpras & 1,446 & 0,000 & 4,248 & $1,945-9,280$ \\
$\begin{array}{l}\text { Informasi } \\
\text { tentang rujukan }\end{array}$ & $-2,444$ & 0,000 & & \\
Konstanta & & & & \\
\hline
\end{tabular}

Variabel yang paling besar pengaruhnya dalam penelitian ini adalah variabel ketersediaan sarana prasarana, informasi tentang rujukan dan pengetahuan. Variabel ketersediaan sarana prasarana mempunyai nilai $\operatorname{Exp}(\mathrm{B}) / \mathrm{OR}=6,810$ artinya responden yang menyatakan ketersediaan sarana prasarana di rumah sakit memadai, berpeluang memilih untuk dirujuk sebesar 6,8 kali lebih tinggi dibandingkan responden yang menyatakan ketersediaan sarana prasarana di rumah sakit tidak memadai.

Variabel informasi tentang rujukan mempunyai nilai $\operatorname{Exp}(B) / O R=4,248$ artinya responden yang mendapat informasi tentang rujukan dalam kategori kurang baik berpeluang memilih untuk dirujuk sebesar 4,2 kali lebih tinggi 


\begin{tabular}{l|c|c}
\hline Jurnal Penelitian Kesmasy & Vol. 2 No. 1 & Edition: May - October 2019 \\
\hline \multirow{2}{*}{ Received: 24 October 2019 } & http://ejournal.delihusada.ac.id/index.php/JPKSY & \multirow{2}{*}{ Accepted: 31 October 2019 } \\
\cline { 2 - 3 } & Revised: 28 October 2019 &
\end{tabular}

dibandingkan responden yang mendapat informasi tentang rujukan dalam kategori baik.

Variabel pengetahuan mempunyai nilai $\operatorname{Exp}(B) / O R=2,588$ artinya responden yang berpengetahuan kurang berpeluang memilih untuk dirujuk sebesar 2,5 kali lebih tinggi dibandingkan responden yang berpengetahuan baik. Berdasarkan hasil uji regresi logistik berganda tersebut juga menunjukkan variabel yang tidak berpengaruh terhadap rujukan ke FKTL karena memiliki nilai signifikan $>0,05$ adalah variabel motivasi $(p=0,074)$ dan sikap tenaga kesehatan $(0,083)$. Selengkapnya dapat dilihat pada tabel berikut.

Tabel 9. Hasil Uji Regresi Logistik Berganda yang Tidak Signifikan

\begin{tabular}{clc}
\hline No. & \multicolumn{1}{c}{ Variabel } & Sig. $(p$-value) \\
\hline 1. & Motivasi & 0,074 \\
2. & Sikap tenaga kesehatan & 0,083 \\
\hline
\end{tabular}

\section{Pengaruh Pengetahuan Terhadap Rujukan ke FKTL}

Berdasarkan hasil penelitian menunjukkan bahwa terdapat pengaruh yang signifikan antara pengetahuan terhadap rujukan ke FKTL di Puskesmas Pancur Batu Kabupaten Deli Serdang tahun 2019, $p=0,008<0,05$. Variabel pengetahuan mempunyai nilai $\operatorname{Exp}(B) / O R=2,588$ artinya responden yang berpengetahuan kurang berpeluang memilih untuk dirujuk sebesar 2,5 kali lebih tinggi dibandingkan responden yang berpengetahuan baik.

Hasil penelitian ini sejalan dengan penelitian Simanjuntak di Puskesmas Medan Johor mendapatkan hasil bahwa variabel pengetahuan mempunyai hubungan signifikan terhadap angka rujukan adalah variabel $(p=0,011<p=0,05)$ (Simanjuntak, 2018). Penelitian Nursafadi wilayah kerja Puskesmas Jumpandang Baru mendapatkan hasil $28 \%$ pengetahuan cukup dan $72 \%$ pengetahuan kurang. Hasil uji statistik ada hubungan pengetahuan responden dengan pemanfaatan pelayanan BPJS Kesehatan (Nursafa, Balqis, \& Palutturi, 2015).

Sistem rujukan pelayanan kesehatan adalah penyelenggaraan pelayanan kesehatan yang mengatur pelimpahan tugas dan tanggung jawab pelayanan kesehatan secara timbal balik baik vertikal maupun horizontal yang wajib dilaksanakan oleh peserta jaminan kesehatan dan seluruh fasilitas kesehatan. Pengetahuan masyarakat (pasien) tentang sistem rujukan sangat penting dalam mengimplementasikan rujukan berjenjang sesuai dengan ketentuan (Alawi, Junadi, \& Latifah, 2015).

Menurut peneliti, berdasarkan hasil penelitian ini menunjukkan bahwa pengetahuan pengguna JKN PBI berpengaruh signifikan dengan rujukan ke fasilitas kesehatan tingkat lanjut di Puskesmas Pancur Batu. Pengguna JKN PBI yang berpengetahuan baik tentang rujukan, maka ia akan cenderung memilih untuk dirujuk jika menderita sakit yang tidak dapat ditangani di Puskesmas Pancur Batu. Tetapi jika penyakit tersebut dapat ditangani di puskesmas maka ia lebih memilih berobat di puskesmas. Tingkat pengetahuan responden juga berkaitan dengan tingkat pendidikannya. Pendidikan merupakan faktor yang secara tidak langsung turut mempengaruhi pola pikir, pemahaman, dan pengetahuannya sehingga juga akan mempengaruhi keluarga dalam pemanfaatan puskesmas. Seseorang yang memiliki pendidikan yang tinggi maka akan memiliki pengetahuan dan pemikiran yang lebih baik dalam mengolah informasi sehingga dapat mempengaruhi keputusannya untuk dirujuk atau tidak dirujuk berdasarkan jenis penyakit yang dideritanya.

Adanya pilihan untuk memanfaatkan rujukan atau tidak memanfaatkan rujukan ke fasilitas kesehatan tingkat lanjut merupakan suatu bentuk nyata yang berhubungan dengan pengetahuan yang dimiliki oleh pasien di Puskesmas Pancur Batu Kabupaten Deli Serdang. Berdasarkan jawaban responden dalam penelitian ini bahwa masih ada responden yang beranggapan bahwa pasien boleh langsung merujuk dirinya sendiri jika pasien merasa tidak cocok dengan pelayanan di Puskesmas. Hal yang sebenarnya adalah pasien tidak boleh menentukan sendiri tempat rujukan, dan harus berdasarkan pertimbangan dari dokter serta kondisi peralatan di puskesmas apakah sesuai dengan penyakit yang dideritanya.

\section{Motivasi Tidak Berpengaruh Terhadap Rujukan ke FKTL}

Berdasarkan hasil penelitian menunjukkan variabel motivasi tidak berpengaruh terhadap rujukan ke FKTL di Puskesmas Pancur Batu Kabupaten Deli Serdang tahun 2019 karena pada analisis regresi logistik berganda memiliki nilai $p$ $=0,074>0,05$. Variabel motivasi tidak berpengaruh karena pasien yang meminta rujukan ke FKTL bukan karena motivasi dari dalam dirinya tetapi berdasarkan penyakit yang dideritanya layak untuk dirujuk atau tidak.

Sejalan dengan penelitian yang dilakukan oleh Kesumawati di 2 puskesmas Kota Sukabumi Provinsi Jawa Barat menunjukkan bahwa di 


\begin{tabular}{l|r|r}
\hline Jurnal Penelitian Kesmasy & Vol. 2 No. 1 & Edition: May - October 2019 \\
\hline \multirow{2}{*}{ Received: 24 October 2019 } & http://ejournal.delihusada.ac.id/index.php/JPKSY & \\
\cline { 2 - 2 } & Revised: 28 October 2019 & Accepted: 31 October 2019
\end{tabular}

Puskesmas Nanggeleng Provinsi Jawa Barat memiliki rasio angka rujukan di atas standar PT. Askes 15\% sedangkan di Puskesmas Gedong Panjang Provinsi Jawa Barat $<15 \%$. Faktor motivasi tidak berhubungan dengan rujukan pasien (Kesumawati, 2012).

Motivasi didefinisikan sebagai dorongan. Dorongan merupakan suatu gerak jiwa dan perilaku seseorang untuk berbuat. Sedangkan motif dapat dikatakan suatu driving force yang artinya sesuatu yang dapat menggerakkan manusia untuk melakukan tindakan atau perilaku, dan di dalam tindakan tersebut terdapat tujuan tertentu. Pengertian dari motivasi tercakup berbagai aspek tingkah atau perilaku manusia yang dapat mendorong seseorang untuk berperilaku atau tidak berperilaku. Namun dalam istilah berikut ini, motivasi adalah dorongan manusia untuk bertindak dan berperilaku (Umam, 2015).Faktor yang dapat mempengaruhi kepuasan pasien adalah kualitas pelayanan yang diterima, fasilitas pelayanan, suasana dan komunikasi yang terjalin selama berada di puskesmas, sedangkan motivasi dapat diartikan membangkitkan motif, membangkitkan daya gerak, atau menggerakkan seseorang atau diri sendiri untuk berbuat sesuatu dalam rangka mencapai suatu kepuasan atau tujuan (Niven, 2014).

\section{Sikap Petugas Kesehatan Tidak Berpengaruh Terhadap Rujukan ke FKTL}

Berdasarkan hasil penelitian menunjukkan variabel sikap petugas kesehatan tidak berpengaruh terhadap rujukan ke FKTL di Puskesmas Pancur Batu Kabupaten Deli Serdang tahun 2019 karena pada analisis regresi logistik berganda memiliki nilai $p=0,083>0,05$. Variabel sikap petugas kesehatan tidak berpengaruh karena rujukan pasien ke FKTL bukan karena sikap petugas kesehatan di Puskesmas Pancur Batu tetapi karena pelayanan yang diberikan di tempat rujukan lebih baik dibandingkan di Puskesmas Pancur Batu.

Penelitian ini sejalan dengan hasil penelitian yang dilakukan oleh Simanjuntak di Puskesmas Medan Johor yang mendapatkan hasil bahwa variabel sikap petugas kesehatan tidak berpengaruh terhadap rujukan pasien di Puskesmas Medan Johor (Simanjuntak, 2018).

Sikap adalah reaksi atau respon seseorang yang masih tertutup terhadap suatu objek (Azwar, 2015). Meningkatnya interaksi petugas kesehatan dengan pasien setelah memperoleh informasi. Kepuasan pasien sangat erat kaitannya dengan sikap yang diterapkan tenaga kesehatan dalam berhubungan dengan pasien. Sikap tenaga kesehatan yang tidak baik akan mempengaruhi pelayanan kesehatan yang diberikan, misalnya tenaga kesehatan yang kurang ramah, kurang komunikatif, sikapnya cenderung acuh tak acuh, tenaga kesehatan yang tidak mengenalkan identitasnya dengan jelas dan tidak menggunakan cara yang baik saat berkomunikasi, sehingga tidak terbina hubungan saling percaya antara tenaga kesehatan dengan pasien (Niven, 2014).

Hasil penelitian ini juga tidak sejalan dengan pendapat Bustami (2017), bahwa attitudes (sikap) petugas kesehatan yang baik memberikanandil atau pengaruh yang besar pada masyarakat atau pasien. Selain itu, sikappetugas juga berpengaruh terhadap psikologi pasien. Hal ini karena pasien yangdatang ke puskesmas berharap cepat sembuh dengan sikap petugas yang ramahmaka pasien merasa puas dengan pelayanan kesehatan yang diberikan sehinggasecara tidak langsung kepuasan mereka berpengaruh terhadap kesembuhan pasiendan kualitas pelayanan puskesmas.

\section{Jarak Tidak Berpengaruh Terhadap Rujukan ke FKTL}

Berdasarkan hasil penelitian menunjukkan variabel jarak tidak berpengaruh terhadap rujukan ke FKTL di Puskesmas Pancur Batu Kabupaten Deli Serdang tahun 2019 karena pada analisis bivariat dengan uji Chi-Square memiliki nilai $\mathrm{p}=$ $0,361>0,05$. Variabel jarak tidak berpengaruh karena pasien lebih banyak yang jarang rumahnya lebih dekat ke puskesmas dibandingkan ke rumah sakit sehingga tidak meminta rujukan ke FKTL.

Berbeda dengan penelitian Alawi (2015) pada pasien Jaminan Kesehatan Nasional pada Puskesmas di Kabupaten Sukabumi menunjukkan adanya perbedaan rerata yang paling tinggi dari variabel jarak dengan $\mathrm{p}$ value 0,003 dan mean difference 14,6 artinya jarak puskesmas terhadap pelayanan kesehatan rujukan memiliki pengaruh terhadap keputusan dokter untuk merujuk kasus-kasus non spesialistik. Semakin dekat Puskesmas dengan fasilitas rujukan maka akan semakin banyaknya rujukan kasus non spesialistik baik itu yang dilakukan oleh dokter Puskesmas maupun oleh masyarakat itu sendiri.

Menurut Alawi, faktor jarak sangat berperan dalam pemanfaatan pelayanan kesehatan. Dalam hal tingginya rujukan kasus non spesialistik di Kabupaten Sukabumi bisa disebabkan oleh lebih dekatnya Puskesmas ke fasilitas rujukan sehingga pasien lebih memilih untuk memanfaatkan layanan kesehatan di fasilitas rujukan (Alawi et 


\begin{tabular}{l|c|c}
\hline Jurnal Penelitian Kesmasy & Vol. 2 No. 1 & Edition: May - October 2019 \\
\hline \multirow{2}{*}{ Received: 24 October 2019 } & http://ejournal.delihusada.ac.id/index.php/JPKSY & \\
\cline { 2 - 2 } & Revised: 28 October 2019 & Accepted: 31 October 2019
\end{tabular}

al., 2015). Rendahnya utilisasi (penggunaan) fasilitas kesehatan seperti Puskesmas, Rumah Sakit, Balai pengobatan, dan sebagainya tidak hanya disebabkan oleh faktor jarak antara fasilitas tersebut. Masyarakat yang terlalu jauh (baik jarak secara fisik maupun sosial), tarif yang tinggi, pelayanan yang tidak memuaskan dan sebagainya, tetapi juga dipengaruhi oleh faktor masyarakat itu sendiri, diantaranya persepsi atau konsep dari masyarakat (Notoatmodjo, 2016).

\section{Ketersediaan Sarana Prasarana Berpengaruh Terhadap Rujukan ke FKTL}

Berdasarkan hasil penelitian menunjukkan bahwa terdapat pengaruh yang signifikan antara ketersediaan sarana prasarana terhadap rujukan FKTL di Puskesmas Pancur Batu Kabupaten Deli Serdang 2019, $p=0,000<0,05$. Variabel ketersediaan sarana prasarana mempunyai nilai $\operatorname{Exp}(B) / O R=6,810$ artinya responden yang menyatakan ketersediaan sarana prasarana di rumah sakit memadai, berpeluang memilih untuk dirujuk sebesar 6,8 kali lebih tinggi dibandingkan responden yang menyatakan ketersediaan sarana prasarana di rumah sakit tidak memadai.

Penelitian ini sejalan dengan penelitian yang dilakukan Lesmana di Puskesmas di Provinsi Daerah Istimewa Yogyakarta dan Jawa Tengah mendapatkan hasil bahwa terdapat hubungan antara ketersediaan alat medis, ketersediaan obat, dengan rasio rujukan non spesialistik (Lesmana, 2016). Penelitian yang dilakukan Alawi menunjukkan bahwa ada hubungan antara kecukupan alat kesehatan di Puskesmas dengan tingginya rujukan kasus non spesialistik dengan nilai p-value 0,024 dengan koefisien korelasi sebesar 0,285 (Alawi et al., 2015). Penelitian Kusumawati menunjukkan bahwa ketersediaan fasilitas alat kesehatan mempengaruhi pelaksanaan sistem rujukan. Begitu pentingnya alat kesehatan yang harus ada di Puskesmas karena fungsinya sangat erat dengan tugas dokter dalam mencegah, mendiagnosis, menyembuhkan dan meringankan penyakit, merawat orang sakit, memulihkan kesehatan pada manusia, dan/atau membentuk struktur dan memperbaiki fungsi tubuh. Ketiadaan atau kekurangan alat kesehatan akan mengurangi dan menghambat tugas dokter dalam melaksanakan pekerjaannya (Kesumawati, 2012). Hasil penelitian ini berbeda dengan hasil penelitian Simanjuntak di Puskesmas Medan Johor mendapati hasil bahwa sebanyak 64 responden $(64,0 \%)$ berpendapat ketersediaan sarana dan prasarana di Puskesmas Medan Johor termasuk kedalam kategori baik, sedangkan 36 responden $(36,0 \%)$ lainnya berpendapat bahwa ketersediaan sarana dan prasarana Puskesmas Medan Johor tidak baik. Tidak ada hubungan antara ketersediaan sarana dan prasarana terhadap rujukan di Puskesmas Medan Johor.

Menurut peneliti, berdasarkan hasil penelitian ini membuktikan bahwa ketersediaan sarana prasarana berpengaruh terhadap rujukan pasien pengguna JKN PBI ke fasilitas kesehatan tingkat lanjut. Sarana prasarana di tempat rujukan yang lebih lengkap menjadi salah satu alasan pasien dirujuk ke FKTL. Pada umumnya pengguna JKN PBI merasa lebih senang jika mendapatkan perawatan di rumah sakit (fasilitas kesehatan tingkat lanjut) walaupun penyakit masih bisa ditangani di Puskesmas Pancur Batu. Hal ini disebabkan sarana prasarana di fasilitas kesehatan tingkat lanjut lebih lengkap dibandingkan dengan di Puskesmas Pancur Batu. Sarana dan prasarana yang tidak lengkap di Puskesmas Pancur Batu misalnya untuk pasien penyakit mata, tidak bisa dilakukan pemeriksaan lebih intensif di Puskesmas Pancur Batu dan baru bisa dilakukan di fasilitas kesehatan tingkat lanjut. Demikian juga dengan penyakit-penyakit lainnya sakit jantung, ginjal, dan lain-lain. Selain peralatan, obat-obatan yang ada di puskesmas juga dianggap kurang bagus, karena masyarakat sering mengalami kebingungan, pasien dengan jenis penyakit yang berbeda tetapi mendapatkan jenis obat yang sama.

\section{Informasi tentang Rujukan Berpengaruh Terhadap Rujukan ke FKTL}

Berdasarkan hasil penelitian menunjukkan bahwa terdapat pengaruh yang signifikan antara informasi tentang rujukan terhadap rujukan FKTL di Puskesmas Pancur Batu Kabupaten Deli Serdang 2019, $p=0,000<0,05$. Variabel informasi tentang rujukan mempunyai nilai $\operatorname{Exp}(B) / O R=4,248$ artinya responden yang mendapat informasi tentang rujukan dalam kategori kurang baik berpeluang memilih untuk dirujuk sebesar 4,2 kali lebih tinggi dibandingkan responden yang mendapat informasi tentang rujukan dalam kategori baik.

Hasil penelitian ini sejalan dengan penelitian yang dilakukan Sopardi Kabupaten Labuhanbatu yang menyatakan bahwa ada hubungan yang signifikan antara informasi dengan pemanfaatan Jamkesmas oleh masyarakat. Informasi berkaitan dengan tingkat pengetahuan, seseorang akan berbeda bergantung pada ketertarikan atau keingintahuannya. Ketertarikan tersebut ditujukan dari intensitas interaksi dirinya terhadap sumber informasi. Semakin tinggi intensitas dirinya untuk 


\begin{tabular}{l|r|r}
\hline Jurnal Penelitian Kesmasy & Vol. 2 No. 1 & Edition: May - October 2019 \\
\hline & http://ejournal.delihusada.ac.id/index.php/JPKSY & \\
\cline { 2 - 2 } Received: 24 October 2019 & Revised: 28 October 2019 & Accepted: 31 October 2019
\end{tabular}

mencari tahu, maka akan semakin meningkat pengetahuannya (Sopar, 2011).

Demikian juga penelitian yang dilakukan oleh Simanjuntak di Puskesmas Medan Johor mendapatkan hasil bahwa variabel informasi rujukan mempunyai hubungan signifikan terhadap angka rujukan $(p=0,008<0,05)$. Berdasarkan hasil penelitian, responden banyak yang tidak pernah mendapatkan informasi mengenai prosedur layanan rujukan serta alur pelaksanaan rujukan. Sebagaimana yang telah ditetapkan oleh BPJS diketahui bahwa prosedur layanan rujukan harus sesuai dengan alur pelaksanaan rujukan agar tidak menyebabkan tingginya angka rujukan di pelayanan kesehatan tingkat primer dan juga tidak mengalami penumpukan pelayanan kesehatan di tingkat sekunder yaitu Rumah sakit. Kurangnya informasi yang diterima pasien mengenai penyakit apa saja yang bisa dirujuk menyebabkan pasien lebih memilih berobat ke pelayanan tingkat sekunder dikarenakan rendahnya tingkat kepercayaan pasien untuk berobat di pelayanan kesehatan primer (Simanjuntak, 2018).

Menurut peneliti, berdasarkan hasil penelitian ini menunjukkan bahwa informasi kesehatan berpengaruh terhadap rujukan pengguna JKN PBI ke fasilitas kesehatan tingkat lanjut. Hal ini disebabkan oleh karena informasi yang benar dan tepat akan membuat pasien pengguna JKN PBI lebih memahami alur rujukan berjenjang di puskesmas ke fasilitas kesehatan tingkat lanjut. Tetapi pada faktanya, sebagian responden menyatakan tidak mendapatkan informasi yang memadai tentang rujukan dan alur rujukan yang tepat. Informasi tentang alur rujukan pasien JKN penting untuk diketahui oleh semua pengguna JKN PBI agar tidak meminta rujukan dan tempat rujukan berdasarkan kehendak pasien tetapi ditentukan oleh pihak puskesmas atau rumah sakit ataupun ketentuan dari pihak BPJS itu sendiri.

\section{KESIMPULAN}

Variabel yang paling besar pengaruhnya dalam penelitian ini adalah variabel ketersediaan sarana prasarana, informasi tentang rujukan dan pengetahuan. Variabel ketersediaan sarana prasarana mempunyai nilai $\operatorname{Exp}(B) / O R=6,810$ artinya responden yang menyatakan ketersediaan sarana prasarana di rumah sakit memadai, berpeluang memilih untuk dirujuk sebesar 6,8 kali lebih tinggi dibandingkan responden yang menyatakan ketersediaan sarana prasarana di rumah sakit tidak memadai.
Tiga variabel yang berpengaruh terhadap rujukan pengguna JKN PBI ke Fasilitas Kesehatan Tingkat Lanjut karena sarana prasarana, informasi tentang rujukan, dan pengetahuan menjadi alasan utama orang melakukan rujukan ke FKTL. Variabel jarak, motivasi, dan sikap tenaga kesehatan di puskesmas tidak mempengaruhi keputusan pasien untuk meminta rujukan karena pasien melihat sarana dan prasarana merupakan hal utama untuk mendapatkan pelayanan yang diinginkan dan sesuai dengan penyakit yang dideritanya.

\section{DAFTAR PUSTAKA}

Alawi, M., Junadi, P., \& Latifah, S. N. (2015). Analisis Faktor-Faktor yang Berhubungan dengan Tingginya Rujukan Kasus Non Spesialistik Pasien Jaminan Kesehatan Nasional pada Puskesmas di Kabupaten Sukabumi Tahun 2015. Jurnal Ekonomi Kesehatan Indonesia, 2(1), 17-23.

Andersen, R., \& Newman, J. F. (1973). Equity In Health: Empirical Analysis in Social Policy. London: Cambridge Mall Bailinger Publishing.

Azwar, S. (2015). Sikap Manusia: Teori dan Pengukurannya. Yogyakarta: Pustaka Pelajar.

BPJS. (2017). Resmi, Pemerintah Kabupaten Deli Serdang Integrasikan Jamkesda 2018 dalam Program JKN.

BPJS. (2018). Jaminan Kesehatan Semesta sudah di Depan Mata.

BPJS Kesehatan. (2014). Panduan Praktis Sistem Rujukan Berjenjang. In Sistem Rujukan Berjenjang. Jakarta.

Jamkes Indonesia. (2019). Tingkat Rujukan ke RS Tinggi.

Kesumawati, I. N. (2012). Analisis Pelaksanaan Rujukan RJTP Peserta ASKES (PERSERO) Kantor Cabang Suka Bumi di Puskesmas Nanggelang dan Gedong Panjang Tahun 2012. Universitas Indonesia.

Kurniawan, Y. T. (2017). Faktor-faktor dan Pola Hubungannya yang Mempengaruhi Pemanfaatan Jaminan Kesehatan Nasional (JKN) oleh Keluarga Miskin. Cakrawala Journal, 11(1), 83-93.

Lesmana. (2016). Faktor-Faktor Yang Berhubungan Dengan Rasio Rujukan Non Spesialistik Pasien BPJS Kesehatan Di Puskesmas Di Provinsi DIY Dan Jawa 


\begin{tabular}{l|c|c}
\hline Jurnal Penelitian Kesmasy & Vol. 2 No. 1 & Edition: May - October 2019 \\
\hline \multirow{2}{*}{ Received: 24 October 2019 } & http://ejournal.delihusada.ac.id/index.php/JPKSY & \multirow{2}{*}{ Accepted: 31 October 2019 } \\
\cline { 2 - 3 } & Revised: 28 October 2019 & \\
\hline
\end{tabular}

Tengah. Universitas Gadjah Mada.

Niven, N. (2014). Psikologi Kesehatan Keperawatan Pengantar untuk Perawat. Jakarta: EGC.

Notoatmodjo, S. (2016). Promosi Kesehatan dan Ilmu Perilaku Kesehatan (Cetakan II). Jakarta: Rineka Cipta.

Nursafa, A., Balqis, \& Palutturi, S. (2015). Faktor yang Berhubungan dengan Pemanfaatan Pelayanan Kesehatan Pasien BPJS Kesehatan di Puskesmas Jumpandang Baru. Universitas Hasanuddin.

Puskesmas Pancur Batu. (2018). Jumlah Peserta JKN di Puskesmas Pancur Batu Kabupaten Deli Serdang. Pancur Batu.

Puskesmas Pancur Batu. (2019a). Data Kunjungan dan Rujukan Pasien di Puskesmas Pancur Batu Periode Juli 2018 - Desember 2018. Pancur Batu.

Puskesmas Pancur Batu. (2019b). Data Sepuluh
Penyakit Tertinggi di Puskesmas Pancur Batu. Pancur Batu.

Rumengan, D. S. S., Umboh, J. M. L., \& Kandou, G. D. (2015). Faktor-Faktor yang Berhubungan dengan Pemanfaatan Pelayanan Kesehatan Pada Peserta BPJS Kesehatan di Puskesmas Paniki Bawah Kecamatan Mapanget Kota Manado. Jikmu Suplemen, 05(1), 88-100. Simanjuntak, Y. (2018). Faktor-Faktor Yang Mempengaruhi Rujukan Pasien BPJS Di Puskesmas Medan Johor Kecamatan Medan Johor Tahun 2017. Universitas Sumatera Utara.

Sopar. (2011). Analisis Faktor-Faktor yang Memengaruhi Pemanfaatan Program Jamkesmas di Kabupaten Labuhanbatu. Universitas Sumatera Utara.

Umam, K. (2015). Perilaku Organisasi. Bandung: Pustaka Setia.

Wartaekonomi. (2018). Program JKN-KIS di 4 Kabupaten Sumut Capai UHC. 